\title{
The Relationship Between Emotional Intelligence and Internet Addiction Among Youth and Adults
}

\author{
Jorge Saraiva, MS O Graça Esgalhado, PhD $\bigcirc$ Henrique Pereira, PhD $\bigcirc \mathrm{Samuel}$ Monteiro, PhD $\mathrm{P}$ \\ Rosa Marina Afonso, PhD $\bigcirc$ Manuel Loureiro, PhD
}

\begin{abstract}
This study aimed to compare emotional intelligence (EI) levels and Internet addiction (IA) by gender and age groups and to assess the predictive relationship between $\mathrm{EI}$ and IA. One thousand four hundred thirteen young people and adults participated in the study. Participants were between 17 and 81 years old $(M=38.70$ years old, $S D=13.72$ years old); $42.2 \%$ were male, whereas $57.5 \%$ were female. We used a sociodemographic questionnaire, the Schutte Emotional Intelligence Scale (Schutte, Malouff, \& Bhullar, 2009), and the Internet Addiction Test (Young, 1998) as data collection instruments. Results showed that there is a weak, but statistically significant, negative relationship between $E I$ and IA. We found higher levels of $E I$ in older people and in women than in the youngest participants and in men. No relevant prevalence of IA was found in the participants of this study.
\end{abstract}

Keywords: adults, emotional intelligence, internet addiction, youth

\section{INTRODUCTION}

Emotional intelligence and Internet addiction are inversely associated, as indicated by several studies showing that individuals with high emotional intelligence levels are less likely to be addicted to the Internet (Beranuy, Oberst, Carbonell, \& Chamarro, 2009; Hamissi, Babaie, Hosseini, \& Babaie, 2013; Parker, Taylor, Eastabrook, Schell, \& Wood, 2008). Emotional intelligence is also related to one's personality, social relationships, and life satisfaction (Hamissi et al., 2013), whereas Internet addiction is associated with various diseases, including depression or phobic anxiety, as well as a number of

\footnotetext{
Jorge Saraiva, MS, Graça Esgalhado, PhD, Henrique Pereira, PhD, Samuel Monteiro, PhD, Rosa Marina Afonso, PhD, and Manuel Loureiro, PhD, Faculty of Human and Social Sciences, Department of Psychology and Education, University of Beira Interior, Covilhã, Portugal.

The authors report no conflicts of interest. The authors alone are responsible for the content and writing of the article.

Correspondence related to content to: Henrique Pereira, PhD, Faculty of Human and Social Sciences, Department of Psychology and Education, University of Beira Interior, Estrada do Sineiro, S/N, 6200-209 Covilhã, Portugal.

E-mail: hpereira@ubi.pt
}

DOI: 10.1097/JAN.0000000000000209 psychosocial risk factors, such as hostility and social isolation (Beranuy et al., 2009).

Internet addiction is assumed to be a very broad concept, and there is no conclusive definition or consensus about this phenomenon. Despite the commitment to achieve a uniform definition and its inclusion in the Diagnostic and Statistical Manual of Mental Disorders, Fifth Edition, researchers and clinicians have encountered difficulties in designating Internet addiction as an impulse control disorder (Block, 2008; Negovan, 2010; Oktuğ, 2010).

In this context, Silva (2014) asserts that many Portuguese teenagers and young adults spend too much time using computers, mobile devices, and the Internet. This study reveals that nearly three quarters of the population under 25 years old show signs of dependence on the digital world. In the most extreme cases, online addiction can result in isolation and violent behaviors and may require psychiatric treatment (Silva, 2014). When addressing the topic of Internet addiction, the results of Pontes, Griffiths, and Patrão (2013) show that the presence of Internet addiction in Portuguese adolescents and young adults between the ages of 15 and 39 years attending secondary school and university is correlated with depressive symptoms and sociodemographic factors, including gender, marital status, age, and level of education.

A variety of studies have shown the impact of Internet addiction on a broad range of behavioral and psychological aspects (Chak \& Leung, 2004; Cho et al., 2010; Douglas et al., 2008; Mesgarani, Shafiee, Ahmadi, \& Zare, 2013; Ying \& Wenbin, 2011). In addition, other researchers studied the impact of Internet addiction on characteristics such personality, loneliness, social support, motivational factors, and so forth among individuals of different ages and different behavioral levels (Bargh \& McKenna, 2004; Hardie \& Yi Tee, 2007; Jahanian \& Seifury, 2008; Romano, Osborne, Truzoli, \& Reed, 2013; Samarein et al., 2013).

In this context, Parker (2005) found that emotional intelligence is a substantial predictor of dependencies associated with addictive behaviors, such as online gaming and Internet use, regardless of age. The author concluded that individuals with lower interpersonal skills spend more time on addictive activities and therefore do not develop interpersonal skills consistent with their age group. 
In addition, this addiction can interfere adversely with personality traits, especially among adolescents, and can cause emotional instability and impulsivity. Khoshakhlagh and Faramarzi (2012) observed that emotional intelligence is the best predictor of IA. However, a significant negative relationship also exists between emotional intelligence, mental disorders, and Internet addiction (Nikmanesh, Kazemi, \& Khosravy, 2014).

Therefore, there are various aspects that motivate the importance of this investigation such as (a) relative lack of Portuguese language research concerning the relationship between EI and IA, (b) to promote social awareness regarding the existence of Internet addiction because doubts still remain about whether the addiction is real despite the fact that substantial evidence continues to grow, and (c) that mental health nurses should be more informed, so that they can take the lead in education, prevention, and treatment of Internet addiction, always considering the role of emotional intelligence in supporting their clients (Veiga-Branco \& Lopes, 2012; Wieland, 2014).

In addition, the focus on gender and age is because these variables play a role in almost all spheres of life, from the workplaces to the interpersonal relationships, and the differences in gender and age clearly determine the type of prevention and intervention in the invisible problem of Internet addiction, as confirmed by studies conducted by most authors (Alavi, Maracy, Jannatifard, \& Eslami, 2011; Hasanzadeh, Beydokhti, \& Zadeh, 2012; Shazad \& Bagum, 2012; Silva, 2014). Thus, this study aims to compare EI and IA levels by gender and age groups and to evaluate the relationship and the predictive relation between the EI and IA.

\section{METHODS}

\section{Sample and Setting}

This study involves 1,413 young people and adults between the ages of 17 and 65 years ( $M=38.79$ years, $S D=13.607$ years). Men make up $42.1 \%$ of participants, whereas women comprise $57.7 \%$ of the sample. Concerning professional status, $6.4 \%$ of participants are unemployed, $14 \%$ are students, $12.4 \%$ are both employed and students, $45 \%$ are employed by someone else, $14.2 \%$ are self-employed, $4 \%$ are retired, and 3.2\% have more than one source of employment. In regard to marital status, participants show the following characteristics: single $(34.2 \%)$, married $(38.7 \%)$, cohabiting $(9.1 \%)$, widowers $(1.1 \%)$, affective meaningful commitment with someone $(9.1 \%)$, and divorced $(7.5 \%)$. With respect to formal educational levels, $0.1 \%$ of participants have 4 years of formal education, $0.3 \%$ have 6 years, $2.2 \%$ have 9 years, $12.8 \%$ have 12 years, $32.6 \%$ hold an undergraduate degree, $37.5 \%$ have a master's degree, and $13.7 \%$ possess a doctoral degree.

\section{Procedure}

Data were collected online. A specific link was created for this investigation, and it was disseminated through e-mail, organizational contacts, and social networks. On their home page, the researchers presented the study's objectives and ethical research procedures, which included confidentiality, anonymity of the participants, and informed consent. Data collection took place between October 2014 and February 2015 and was collected from a sample of the Portuguese population. The study conforms to the ethical principles for scientific research, as defined by the Portuguese Psychological Society (Ordem dos Psicólogos Portugueses), as well as the guidelines of the American Psychological Association regarding the conduct of human studies. Subsequently, the data collected were statistically analyzed using the SPSS v.22. The age division of the sample is supported by the research of Papalia, Olds, and Feldman (2009) that emphasizes adult development as a set of specific changes that occur in biological and psychological domains of human life according to each age stage.

\section{Measures}

The data collection instruments used included a sociodemographic questionnaire, the Schutte Emotional Intelligence Scale (Schutte, Malouff, \& Bhullar, 2009), and the Internet Addiction Test (Young, 1998).

The sociodemographic questionnaire aimed to gather demographic information to enable us to characterize the study's participants. Thus, we considered variables such as age, gender, nationality, marital status, and educational level.

The Schutte Emotional Intelligence Scale (Schutte et al., 2009) is measure of emotional intelligence traits and consists of 33 items with a 5-point Likert-type response format. Each item asks participants to indicate their level of agreement, using responses ranging from "strongly disagree" to "strongly agree." The most commonly used subscales are "perception of emotions" (Items 5, 9, 15, 18, 19, 22, 25, 29, 32, and 33), "dealing with our own emotions" (Items 2, 3, 10, 12, 14, $21,23,28$, and 31), "dealing with others' emotions" (Items $1,4,11,13,16,24,26$, and 30), and "use of emotions" (Items $6-8,17,20$, and 27). Factor analysis revealed four factors whose load factor is equal to or above 0.40 . The strength factor and rigorous design of the 33 items were the principal reasons this scale was utilized. The analysis of internal consistency is shown by a Cronbach's alpha of .90, indicating good internal consistency, and the test-retest showed a reliability of .78 (Schutte et al., 1998). The value obtained in this study was .879 , which is consistent with the original study, representing a very high level of internal consistency (Marôco, 2014). The studies conducted by Schutte et al. (1998) showed that the scores in the measurement of 33 items are correlated with eight theoretically related constructs. The total score can vary between 33 and 165 points. The higher the score achieved on this scale, the more easily individuals can be considered emotionally stable. Of the 33 scale items, 5, 28, and 33 are inverted.

The Internet Addiction Test (Young, 1998) is a questionnaire of 20 items in which respondents are asked to score each item on a Likert-type scale of 5 points to assess the degree to which Internet usage affects their daily routines, social life, productivity, and feelings. The minimum score is 20 , and the maximum is 100 . The higher the score, the greater the 
problems caused by Internet use. Young suggests that a score of 20-39 points is a midline where the respondent has full control and shows proper use of the Internet. A score of 40-69 signifies that the respondent shows frequent problems related to Internet usage. Finally, a score of 70-100 means that the respondent's Internet usage is causing significant problems. We extracted six factors from this questionnaire. The first factor (five items) measures the importance of using the Internet. The second factor (five items) measures overuse of the Internet. The third factor (three items) assesses neglect of one's work and professional obligations. The fourth factor (two items) measures anticipation. The fifth factor (three items) describes one's lack of self-control. Finally, the sixth factor (two items) highlights and evaluates the lack of a social life. These factors show low to good consistency, with alpha coefficients ranging from .54 to .82 (Widyanto \& McMurran, 2004). The Cronbach's alpha value obtained in this study (.916) is higher than the value in the original study, which signifies a very high level of internal consistency (Marôco, 2014).

We used parametric tests that required two conditions: the quantitative variables to be normally distributed and the population variances to be homogeneous. This was ensured after using the Kolmogorov-Smirnov test and the Levene test (Marôco, 2014). Student $t$ test was required for comparing means of two different subject groups, and the Pearson correlation coefficient was used as a measure of linear association, with values oscillating between -1 and +1 (Pestana \& Gageiro, 2014). In addition, we used the stepwise multiple regression to predict the behavior of a dependent variable $(y)$ from the independent variables $(x)$, alongside with the margin of error $(95 \%$ confidence interval).

\section{RESULTS}

For EI levels, the average score was $134.48(S D=12: 48)$, and the average for IA levels was 36.10 ( $S D=13: 43)$. In the sample, $67.8 \%$ of participants reported having complete control and proper use of the Internet, whereas $30.2 \%$ had a score that indicates frequent problems relating to their Internet usage, and $1.9 \%$ possessed scores indicating significant problems in relation to Internet use.

Regarding the demographic results, "age" was subdivided into two groups, the "youth" group (adolescents and young adults) between 17 and 30 years and the "older" group between 31 and 65 years. All demographic results are shown in Table 1.

Table 2 shows that male and female participants show statistically significant differences $(t(1385)=-3.734, p<$ $.001)$, with women scoring higher in EI $(M=135.59, S D=$ 13.10) when compared with men $(M=132.88, S D=$ 13.73). Results for all other dimensions are presented in the same table.

Table 3 shows the statistically significant differences among age groups $(t(1349)=-5.906, p<.001)$, in addition to conveying that older participants generally report a higher EI score $(M=136.31, S D=13.38)$ than younger participants
$(M=132.04, S D=13.08)$. Results for all other dimensions are presented in the same table.

Table 4 shows the results regarding the comparison of Internet addiction levels and the dimensions by gender. Statistically significant gender differences are found $(t(1385)=$ $4.558, p<.001)$, with men possessing higher IA scores $(M=$ $37.89, S D=13.83)$ than women $(M=34.81, S D=11.25)$. Results for all other dimensions are presented in the same table.

Table 5 presents the results comparing Internet addiction levels and their dimensions by age. Differences between age groups are statistically significant $(t(1349)=6.348, p<$ $.001)$, and younger participants have higher IA scores $(M=$ $38.47, S D=13.31)$ when compared with older subjects $(M=$ $34.19, S D=11.43)$. Results for all other dimensions are presented in the same table.

The researchers performed a Pearson correlation analysis between the variables and their dimensions. The results presented in Table 6 indicate that the established correlations between the variables of emotional intelligence and Internet addiction are mostly negative and significant. The researchers verified the existence of weak negative correlations, which were also statistically significant for most of the dimensions of the two scales.

As previously noted, we established a weak, but statistically significant, negative correlation $(r=-.184, p<.001)$ in regard to the relationship between emotional intelligence and Internet addiction. Thus, the researchers conducted a linear regression, designating Internet addiction as the dependent variable and emotional intelligence and its dimensions as the independent variables.

Using the stepwise method of linear regression, as shown in Table 7, the dimensions of emotional intelligence are determined to act as predictors of Internet addiction. The results shown are the nonstandardized regression coefficients $(\beta)$, the values of standard error of $\beta$, the standardized regression coefficients $(\beta)$, the $R^{2}$, and the $R^{2}$ set. The adjusted $R^{2}$ explains the $0.41 \%$ of the variability.

The $B$ standard error (EPB) is 0.080 , and the value of $t(t=$ $-7.444, p<.001)$ is significant, signifying that the dimension entered into the regression model ("perception of emotions") has explanatory power in regard to Internet addiction. The second regression model utilizes the dimensions "perception of emotions" and "dealing with others' emotions" as variable predictors of Internet addiction. In this regression model, the value of the adjusted $R^{2}$ explains $0.48 \%$ of the variability. The standard error value of $B(\mathrm{EPB})$ of 0.099 and the value of $t(t=$ $-3.994, p<.001)$ for the "perception of emotions," in addition to the value of $B$ (EPB) of 0.100 and the value of $t(t=$ $-3.303, p=.001)$ for the dimension "dealing with others' emotions," are statistically significant. This suggests that these dimensions of emotional intelligence also have explanatory power in regard to Internet addiction. As can be seen when considering the value of $B$, both the dimension "perception of emotions" $(\beta=-.204, p<.001)$ and the dimension "dealing with others' emotions" $(\beta=-.204, p<.001)$ have a negative influence on Internet addiction. This signifies the 
TABLE 1 Sociodemographic Data

\begin{tabular}{|c|c|c|c|c|}
\hline & & Frequency & $\%$ & Cumulative \% \\
\hline \multirow[t]{2}{*}{ Gender } & Male & 585 & 42.1 & 42.1 \\
\hline & Female & 802 & 57.7 & 99.9 \\
\hline \multirow[t]{7}{*}{ Education level } & 4 years & 1 & 0.1 & 0.1 \\
\hline & 6 years & 4 & 0.3 & 0.4 \\
\hline & 9 years & 31 & 2.2 & 2.6 \\
\hline & 12 years & 178 & 12.8 & 15.5 \\
\hline & Undergraduate & 454 & 32.6 & 48.4 \\
\hline & Master & 522 & 37.5 & 86.2 \\
\hline & Doctoral & 191 & 13.7 & 100.0 \\
\hline \multirow[t]{6}{*}{ Marital status } & Single & 476 & 34.2 & 34.3 \\
\hline & Married & 538 & 38.7 & 73.2 \\
\hline & Cohabiting & 127 & 9.1 & 82.3 \\
\hline & Widower & 15 & 1.1 & 83.4 \\
\hline & $\begin{array}{l}\text { Affective commitment } \\
\text { with someone }\end{array}$ & 126 & 9.1 & 92.5 \\
\hline & Divorced & 104 & 7.5 & 100.0 \\
\hline \multirow[t]{7}{*}{ Profession status } & Unemployed & 89 & 6.4 & 6.4 \\
\hline & Student & 195 & 14.0 & 20.6 \\
\hline & Employed student & 172 & 12.4 & 33.0 \\
\hline & $\begin{array}{l}\text { Employed by someone } \\
\text { else }\end{array}$ & 626 & 45.0 & 78.3 \\
\hline & Self-employed & 198 & 14.2 & 92.7 \\
\hline & Retired & 56 & 4.0 & 96.7 \\
\hline & Other & 45 & 3.2 & 100.0 \\
\hline \multicolumn{2}{|l|}{ Total $(N)$} & 1391 & 100.0 & \\
\hline
\end{tabular}

existence of an inverse relationship, showing a correlation between lower levels of "perception of emotions" and "dealing with others" emotions" and higher levels of Internet addiction.

\section{DISCUSSION}

The sample shows very low levels of Internet addiction, as only $1.9 \%$ of subjects present significant problems in regard to their Internet usage.

The results for gender differences were statistically significant $(t(1385)=-3.734, p<.001)$, because women obtained higher scores than men in the dimensions of emotional intelligence. This complements the study results of Mandell and Pherwani (2003), which also observed significant differences in the average scores of emotional intelligence between men and women. The results are in line with those reported by Extremera, Fernandez-Berrocal, and Salovey (2006), as well as those of Harrod and Scheer (2005), which found that women possessed higher levels of emotional intelligence than men. However, gender differences in EI are not supported by all conducted studies. In fact, Shazad and Bagum (2012) con- cluded that men and women have the same level of emotional intelligence, although they verified the existence of different scores on emotional intelligence subdimensions.

However, most existing results show greater emotional skills in women, which we also could see in this study. In fact, according to recent studies, women have an increased capacity at the level of emotional intelligence not only in general but also in various dimensions of the same, as analysis of emotions, perception, and emotional expression; managing emotions; and also related emotions with cognition (Çelik \& Deniz, 2008; Snowden et al., 2014). Furthermore, emotional intelligence is considered more as a markedly feminine attribute because of the demonstration of greater social skills by women as men, in turn, usually present as more proficient in other areas such as spatial ability (Bueno, Santana, Zerbini, \& Ramalho, 2006; Rooy, Alonso, \& Viswesvaran, 2005).

Regarding the sample's differences in the results concerning age, there were statistically significant differences seen between age groups $(t(1349)=-5.906, p=.000)$. Older participants presented higher scores in all dimensions of 


\begin{tabular}{|c|c|c|c|c|c|c|}
\hline \multirow[t]{2}{*}{ TABLE 2} & \multirow[b]{2}{*}{ Gender } & \multirow{3}{*}{$\begin{array}{c}n \\
585 \\
\end{array}$} & \multirow{3}{*}{$\begin{array}{c}\boldsymbol{M} \\
132.88 \\
\end{array}$} & \multirow{3}{*}{$\begin{array}{c}S D \\
13.73 \\
\end{array}$} & \multirow{3}{*}{$\frac{\boldsymbol{t}(\boldsymbol{d f})}{-3.734(1385)}$} & \multirow{3}{*}{$\frac{p}{.000 * *}$} \\
\hline & & & & & & \\
\hline \multirow[t]{2}{*}{ Total El } & Male & & & & & \\
\hline & Female & 802 & 135.59 & 13.10 & & \\
\hline \multirow[t]{2}{*}{ "Perception of emotions" } & Male & 570 & 36.59 & 4.27 & $-4.516(1339)$ & $.000^{* *}$ \\
\hline & Female & 771 & 37.65 & 4.25 & & \\
\hline \multirow{2}{*}{$\begin{array}{l}\text { "Dealing with our own } \\
\text { emotions" }\end{array}$} & Male & 572 & 35.13 & 3.55 & $-2.324(1351)$ & $.020^{*}$ \\
\hline & Female & 781 & 35.58 & 3.51 & & \\
\hline \multirow[t]{2}{*}{ "Dealing with others' emotions" } & Male & 579 & 31.85 & 4.43 & $-5.324(1366)$ & $.000 * *$ \\
\hline & Female & 789 & 33.09 & 4.08 & & \\
\hline \multirow[t]{2}{*}{ "Use of emotions" } & Male & 574 & 24.56 & 3.25 & $-2.265(1354)$ & $.024^{*}$ \\
\hline & Female & 782 & 24.96 & 3.16 & & \\
\hline
\end{tabular}

emotional intelligence, in comparison with younger members of the study, supporting the empirical evidence found by Extremera et al. (2006). In their research, they found that older individuals possessed more emotional intelligence. These results suggest that life experiences can have a positive impact on the development of emotional intelligence. GaitniecePutane (2009) shows that gender and age can influence emotional intelligence, which was corroborated by the study sample, as older individuals and women showed higher average values of this variable.

Regarding the results of Internet addiction levels and its gender dimensions, the research concluded that gender differences are statistically significant $(t(1385)=4.558, p<.001)$. Men, on average, revealed a higher IA score than women. It should be noted that, in the dimension "lack of control," there was no statistically significant difference $(t(1372)=1.505, p=.133)$; however, men showed a higher score $(M=05.05, S D=2.31)$ when compared with women $(M=4.87, S D=2.17)$. These results corroborate those reported by Chakraborty et al. (2010); Frangos, Frangos, and Sotiropoulos (2011); Kuss, Griffiths, and Binder (2013); and Özcan and Gokcearslan (2013), which found that men showed a higher risk of developing Internet addiction. Alavi et al. (2011) also state that male subjects are inclined to use the Internet more frequently than women, so the risk of Internet addiction in the general male population is about three times higher than in the general female population. Although high levels of Internet addiction are almost nonexistent in our study's sample, our findings still corroborate the results obtained in prior research. The research confirms that women show greater emotional intelligence when compared with men, which is a key indicator of Internet addiction, due to the negative relationship

\begin{tabular}{|c|c|c|c|c|c|c|}
\hline \multirow[t]{2}{*}{ TABLE 3} & $\begin{array}{l}\text { Total E } \\
\text { cipants }\end{array}$ & re a & Rang & Dimen & ns in Younge & \\
\hline & Age Group & $n$ & $M$ & $S D$ & $t(d f)$ & $p$ \\
\hline \multirow[t]{2}{*}{ Total EI } & Younger & 631 & 132.04 & 13.08 & $-5.906(1349)$ & $.000 * *$ \\
\hline & Older & 720 & 136.31 & 13.38 & & \\
\hline \multirow[t]{2}{*}{ "Perception of emotions" } & Younger & 612 & 36.85 & 4.16 & $-2.447(1305)$ & $.015^{*}$ \\
\hline & Older & 695 & 37.44 & 4.40 & & \\
\hline \multirow{2}{*}{$\begin{array}{l}\text { "Dealing with our own } \\
\text { emotions" }\end{array}$} & Younger & 616 & 34.98 & 3.49 & $-3.646(1316)$ & $.000 * *$ \\
\hline & Older & 702 & 35.68 & 3.54 & & \\
\hline \multirow{2}{*}{$\begin{array}{l}\text { "Dealing with others' } \\
\text { emotions" }\end{array}$} & Younger & 622 & 31.92 & 4.19 & $-4.934(1330)$ & $.000 * *$ \\
\hline & Older & 710 & 33.07 & 4.27 & & \\
\hline \multirow[t]{2}{*}{ "Use of emotions" } & Younger & 622 & 24.20 & 3.14 & $-6.187(1319)$ & $.000 * *$ \\
\hline & Older & 699 & 25.28 & 3.16 & & \\
\hline
\end{tabular}


TABLE 4 Results for the Comparison Between Men and Women in the Total Score of the IA and the Subscales

\begin{tabular}{|c|c|c|c|c|c|c|}
\hline & Gender & $n$ & $M$ & SD & $t(d f)$ & $p$ \\
\hline \multirow[t]{2}{*}{ Total IA } & Male & 585 & 37.89 & 13.83 & 4.558 (1385) & $.000 * *$ \\
\hline & Female & 802 & 34.81 & 11.25 & & \\
\hline \multirow{2}{*}{$\begin{array}{l}\text { "Importance of the } \\
\text { Internet use" }\end{array}$} & Male & 580 & 8.24 & 3.95 & 3.569 (1364) & $.000^{* *}$ \\
\hline & Female & 786 & 7.57 & 2.99 & & \\
\hline \multirow[t]{2}{*}{ "Overuse" } & Male & 579 & 10.33 & 3.59 & 3.401 (1367) & $.001 *$ \\
\hline & Female & 790 & 9.69 & 3.37 & & \\
\hline \multirow[t]{2}{*}{ "Negligence at work" } & Male & 569 & 5.08 & 2.54 & 4.229 (1353) & $.000 * *$ \\
\hline & Female & 786 & 4.54 & 2.10 & & \\
\hline \multirow[t]{2}{*}{ "Lack of control" } & Male & 580 & 5.05 & 2.31 & 1.505 (1372) & .0133 \\
\hline & Female & 794 & 4.87 & 2.17 & & \\
\hline \multirow[t]{2}{*}{ "Lack of a social life" } & Male & 580 & 5.71 & 2.61 & 3.344 (1372) & $.001 *$ \\
\hline & Female & 794 & 5.26 & 2.36 & & \\
\hline
\end{tabular}

consistently found between these two variables. Thus, there is a need to implement programs to spur emotional development, not only to facilitate the expression of emotions in men but also to develop protective factors against addictive behaviors when using the Internet.

Concerning the results that compare levels of Internet addiction and its dimensions by age, the researchers found that the differences between age groups are statistically significant as well $(t(1349)=6.348, p<.001)$. On average, the study's younger participants revealed a higher Internet addiction score when compared with older members of the study. These results are consistent with those seen in the literature, which finds that younger individuals, particularly teenagers, are at an increased risk of Internet addiction (Beutel et al., 2011; Chen \& Fu, 2009; Hasanzadeh et al., 2012; Sato, 2006). The study by Silva (2014) also revealed that almost three quarters of the Portuguese population aged 25 years and younger show signs of digital world dependence, especially teens and young adults who, in many cases, spend excessive amounts of time on the Internet. In short, younger participants score lower on

\begin{tabular}{|c|c|c|c|c|c|c|}
\hline \multirow[t]{2}{*}{ TABLE 5} & \multirow{2}{*}{ Age Group } & \multicolumn{2}{|c|}{ rison of the Total } & \multicolumn{2}{|r|}{ 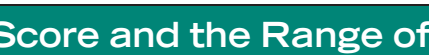 } & \multirow[t]{2}{*}{ ons } \\
\hline & & $n$ & $M$ & $S D$ & $t(d f)$ & \\
\hline \multirow[t]{2}{*}{ Total IA } & Younger & 631 & 38.47 & 13.31 & $6.348(1349)$ & $.000 * *$ \\
\hline & Older & 720 & 34.19 & 11.43 & & \\
\hline \multirow[t]{2}{*}{ "Importance of Internet use" } & Younger & 624 & 8.41 & 3.77 & 5.457 (1329) & $.000 * *$ \\
\hline & Older & 707 & 7.39 & 3.07 & & \\
\hline \multirow[t]{2}{*}{ "Overuse" } & Younger & 624 & 10.53 & 3.70 & $5.504(1331)$ & $.000^{* *}$ \\
\hline & Older & 709 & 9.48 & 3.21 & & \\
\hline \multirow[t]{2}{*}{ "Negligence at work" } & Younger & 624 & 5.17 & 2.46 & $5.888(1318)$ & $.000 * *$ \\
\hline & Older & 696 & 4.43 & 2.11 & & \\
\hline \multirow[t]{2}{*}{ "Lack of control" } & Younger & 627 & 5.30 & 2.12 & $5.403(1337)$ & $.000 * *$ \\
\hline & Older & 712 & 4.65 & 2.28 & & \\
\hline \multirow[t]{2}{*}{ "Lack of a social life" } & Younger & 626 & 5.82 & 2.60 & $5.042(1336)$ & $.000^{* *}$ \\
\hline & Older & 712 & 5.14 & 2.34 & & \\
\hline
\end{tabular}




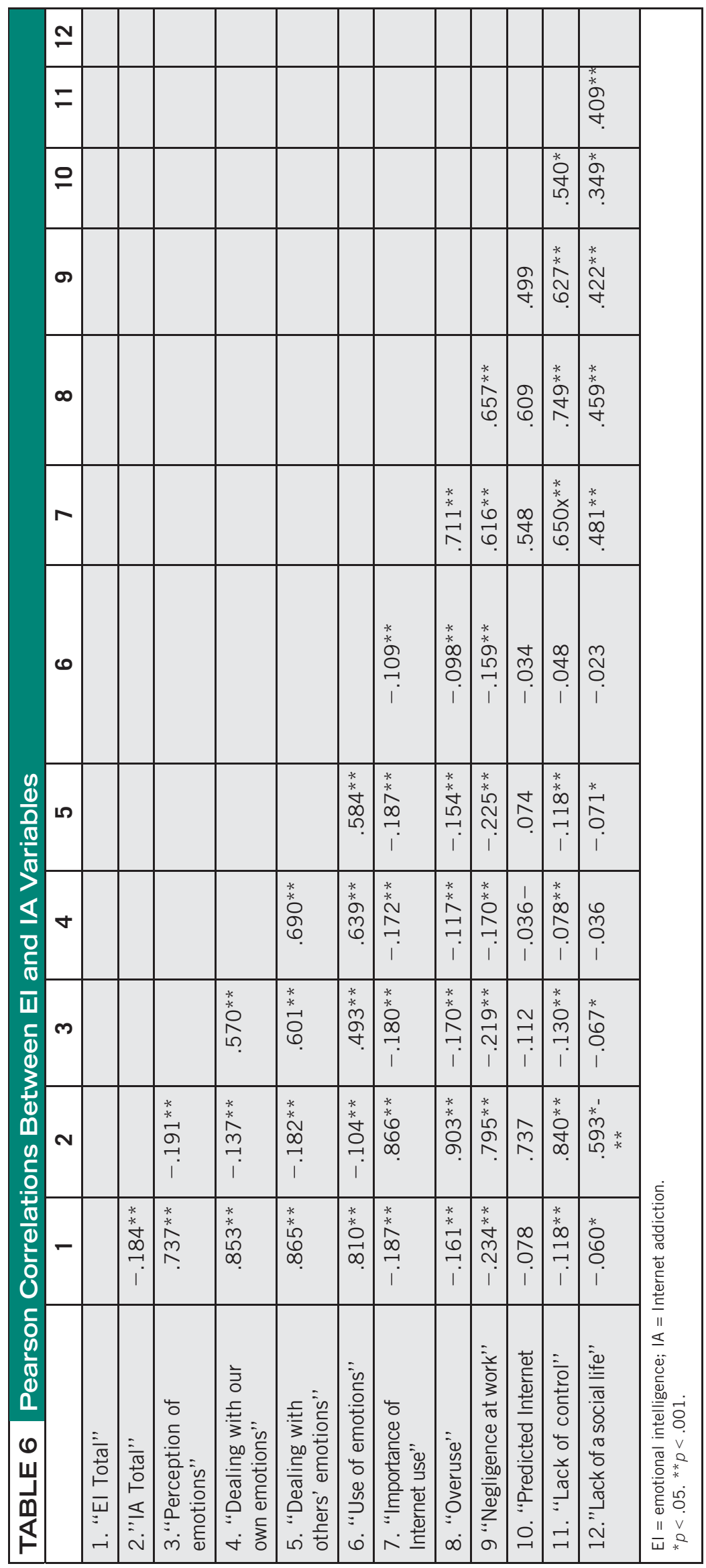


TABLE 7 Stepwise Multiple Regression on the Predictor Effect of Emotional Intelligence in Internet Addiction

\begin{tabular}{|l|l|c|c|c|c|c|c|c|}
\hline & Predictor & $\boldsymbol{R}^{2}$ & $\boldsymbol{R}^{2}$ Adjusted & B & EPB & $\beta$ & $\boldsymbol{t}$ & $\boldsymbol{p}$ \\
\hline Step1 & "Perception of emotions" & .042 & .041 & -.593 & 0.080 & -.204 & -7.444 & .000 \\
\hline \multirow{2}{*}{ Step2 } & "Perception of emotions" & .050 & .048 & -.396 & 0.099 & -.204 & -3.994 & .000 \\
\cline { 2 - 9 } & "Dealing with others' emotions" & -.329 & .100 & -.204 & -3.303 & .001 & -0.329 & .100 \\
\hline
\end{tabular}

emotional intelligence and are the most likely to be addicted to the Internet. In cases of extreme Internet addiction, the development of intervention activities and the promotion of social skills are warranted.

Furthermore, the dimensions "perception of emotions" $(\beta=$ $-.204, p<.001)$ and "dealing with others' emotions" $(\beta=$ $-.204, p<.001)$ show an inverse relationship with levels of Internet addiction. The research indicates that lower levels of "perception of emotions" and "dealing with others' emotions" are correlated with higher occurrences of Internet addiction. In this context, the study of Hamissi et al. (2013) shows that self-assessed emotional intelligence scores have a negative relationship with Internet addiction. In other words, people with high emotional intelligence seem to be able to control their dependence on the Internet, whereas individuals with low emotional intelligence are more likely to show signs of Internet addiction

The correlations established between the variables of emotional intelligence and Internet addiction are weak and negative $(r=-.184, p<.001)$ but statistically significant. The study by Reiso?lu, Gedik, and Goktas (2013) show that emotional intelligence is not a predictor of Internet addiction, which contradicts other findings from the literature as well as those found in this study. Jafari and Fatehizade (2011) corroborate the existence of correlations between Internet addiction and emotional intelligence, claiming that emotional intelligence can reliably predict $29 \%$ of cases of Internet addiction. Data from this study indicate that there is a relationship between these variables. However, it should be noted that this association might vary based on individual and cultural differences.

Contrary to those who display low levels of emotional intelligence, emotionally intelligent individuals will actually be able to create, through the use of emotional regulation, positive emotions controlling the negative and grow emotionally and intellectually and will be better able to establish interpersonal relationships and better control of their own lives (Wong \& Law, 2002).

The negative impact of Internet use on individuals and their lives is often undervalued. Brown (2006) suggested that the choice that individuals make by the technological means is influenced by their character and the way they interact with the world. Thus, the way people interact with the Internet can be reflected in their daily lives, influencing their behavior. Adolescents are more likely to use the Internet as a form of socialization, without realizing the potential negative impact, and when this affects the mood and compromises the function and the academic, professional, and social performance, the use of the Internet can become a problem that requires intervention by psychologists (Yen, Ko, Yen, Chang, \& Cheng, 2009).

In the field of nursing, Wieland (2014) reveals that the nurses are professionals who often interact with clients and identify the problems associated with Internet addiction as the primary failure of well-being or as a secondary problem of other concerns such as anxiety, depression, and so on.

So, the implications for mental health education and interventions are challenging for nurses. On the one hand, nurse educators need to add technological addictions, such as Internet addiction, to the nursing curriculum, and the nursing assessment should include use of screening instruments for this specific addiction such as adapting the Young Internet Addiction Test by Young (1998).

On the other hand, nurses must have emotional intelligence training to know their emotions to effectively manage them and recognize them in others (empathy), to assist the clients to join and progress in the treatment of this addiction, because a key to intervention is the motivation for change, which is particularly problematic with the current reliance on the Internet for people's everyday lives (Fitzpatrick, 2008).

In the perspective of emotional intelligence, nurses should be aware of their own emotions and how these affect them, thereby subsequently managing their own emotions and becoming more effective in their activities, whether personal or professional. So, the emotions underlying the sense of the effectiveness of the decisions from the emotional control are the key for performance in nursing career (Veiga-Branco \& Lopes, 2012).

This study features some limitations. First, the sample was very heterogeneous and was gathered over the Internet. Second, it was a cross-sectional study that warrants caution when generalizing the results obtained. Therefore, further studies in the same field that utilize even broader samples are recommended to corroborate our findings.

Finally, we wish to promote the importance of early intervention in schools through a multidisciplinary approach encompassing parents/guardians, teachers, staff, and so forth. To prevent the development of IA behaviors and stimulate EI, we support increased health education sessions, with the goal of teaching students to use the Internet in a healthy and sustainable manner. The researchers also recommend that connections with social associations, businesses, and public services be enhanced to promote the prevention of Internet addiction. The results obtained support the idea that action should be taken in the form of primary prevention, by warning children, adolescents, and adults about the risks and 
consequences arising from IA, so that they will be self-reliant and responsible with their own mental and physical health.

In conclusion, we consider this work to be an important study on Internet addiction and emotional intelligence, which made us more aware of these phenomena and the role we must play as psychologists to address them accordingly.

\section{REFERENCES}

Alavi, S. S., Maracy, M. R., Jannatifard, F.,\& Eslami, M. (2011). The effect of psychiatric symptoms on the internet addiction disorder in Isfahan's University students. Journal of Research in Medical Sciences, 16(6), 793-800.

Bargh, J.,\& McKenna, K. (2004). The Internet and social life. Annual Review of Psychology, 55(1), 573-590.

Beranuy, M., Oberst, U., Carbonell, X.,\& Chamarro, A. (2009). Problematic internet and mobile phone use and clinical symptoms in college students: The role of emotional intelligence. Computers in Human Behavior, 25(5), 1182-1187.

Beutel, M.E., Brahler, E., Glaesmer, H., Kuss, D. J., Wolfling, K., \& Muller, K. W. (2011). Regular and problematic leisure-time internet use in the community: Results from a German population-based survey. Cyberpsychology, Behavior, and Social Networking, 14(5), 291-296.

Block, J. J. (2008). Issues for the DSM-V: Internet addiction. The American Journal of Psychiatry, 165, 306-307.

Brown, J. D. (2006). Emerging adults in a media-saturated world. In In J. J. Arnett \& J. L. Tanner (Eds.), Emerging adults in America: Coming of age in the 21st century (pp. 279-299). Washington, DC: American Psychiatric Association.

Bueno, J. M., Santana, P. R., Zerbini, J., \& Ramalho, T. B. (2006). Inteligência emocional em estudantes universitários. Psicologia, Teoria e Pesquisa, 22(3), 305-316.

Çelik, S. B., \& Deniz, M. E. (2008). A comparison of scouts' emotional intelligence levels with regards to age and gender variables: A crosscultural study. Elementary Education Online, 7(2), 376-383.

Chak, K., \& Leung, L. (2004). Shyness and locus of control as predictors of internet addiction and internet use. CyberPsychology and Behavior, 7, 559-570.

Chakraborty, K., Basu, D., \& Kumar, K.G.V. (2010). Internet addiction: Consensus, controversies, and the way ahead. East Asian Arch Psychiatry, 20(3), 123-132. Retrieved from http://www.easap.asia/ index.php/docman/v20n3/33-1003-v20n3-p123

Chen, S. Y., \& Fu, Y. C. (2009). Internet use and academic achievement: Gender differences in early adolescence. Adolescence, 44(176), 797-812.

Cho, S. I., Lee, Y. S., Baek, H. T., Han, D. H., Kee, B. S., \& Park, D. B. (2010). Insecure attachment and impulsivity-inattention problem in adolescent with a high risk of substance or internet addiction. Journal on Korean Neuropsychiatric Association, 49, 390-400.

Douglas, A. C., Mills, J. E., Niang, M., Stepchenkova, S., Byun, S., Ruffini, C., \& Blanton, M. (2008). Internet addiction: Meta-synthesis of qualitative research for the decade 1996-2006. Journal on Computers in Human Behavior, 24, 3027-3044.

Extremera, N., Fernandez-Berrocal, P., \& Salovey, P. (2006). Spanish version of the Mayor-Salovey-Caruso Emotional Intelligence test (MSCEIT). Version 2.0: Reliabilities, age and gender differences. Psicothema, 18, $42-48$.

Fitzpatrick, J. J. (2008). Internet addiction: Recognition and interventions. Archives of Psychiatric Nursing, 22(2), 59-60.

Frangos, C. C., Frangos, C. C., \& Sotiropoulos, I. (2011). Problematic internet use among Greek university students: An ordinal logistic regression with risk factors of negative psychological beliefs, pornographic sites, and online games. Cyberpsychology, Behavior, and Social Networking, 14, 51-58.

Gaitniece-Putane, A. (2009). Gender and age differences in emotional intelligence, stoicism and aggression. Baltic Journal of Psychology, 7(2), 26-42.

Hamissi, J., Babaie, M., Hosseini, M., \& Babaie, F. (2013). The relationship between emotional intelligence and technology addiction among university students. International Journal of Collaborative Research on Internet Medicine and Public Health, 5(5), 310-319.

Hardie, E., \& Yi Tee, M. (2007). Excessive internet use: The role of personality, loneliness and social support networks in internet addiction. Australian Journal of Emerging Technologies and Society, 5, 34-44.

Harrod, N. R., \& Scheer, S. D. (2005). An exploration of adolescent emotional intelligence in relation to demographic characteristics. Adolescence, 40(159), 503-512.

Hasanzadeh, R., Beydokhti, A., \& Zadeh, F. D. (2012). The prevalence of Internet addiction among university students: A general or specific problem? Journal of Basic and Applied Scientific Research, 2, 5264-5271.

Jafari, N., \& Fatehizade, M. (2011). Prediction of internet addiction, based on emotional intelligence among Isfahan university students. Knowledge and Research in Applied Psychology, 12(3), 1645-1656.

Jahanian, R., \& Seifury, Z. (2008). The impact of internet addiction on students' mental health in technical and vocational colleges in Alborz Province. Middle-East Journal of Scientific Research, 14(11), 1533-1538.

Khoshakhlagh, H., \& Faramarzi, S. (2012). The relationship of emotional intelligence and mental disorders with internet addiction in internet users university students. Addict Health, 4(4-3), 133-141.

Kuss, D. J., Griffiths, M. D., \& Binder, J. F. (2013). Internet addiction in students: Prevalence and risk factors. Computers in Human Behavior, 29(3), 959-966.

Mandell, B., \& Pherwani, S. (2003). Relationship between emotional intelligence and transformational leadership style: A gender comparison. Journal of Business and Psychology, 17(3), 387-404.

Marôco, J. (2014). Análise estatística com utilização do SPSS. Lisboa, Portugal: Edições Sílabo.

Mesgarani, M., Shafiee, S., Ahmadi, E., \& Zare, F. (2013). Studying the relationship between internet addiction and emotional intelligence, sensation seeking and meta-cognition among those who are referred to cafes. International Research Journal of Applied and Basic Sciences, 5, 889-893.

Negovan, V. (2010). Dimensions of students' psychosocial well-being and their measurement: Validation of a students' psychosocial well being inventory. Europe's Journal of Psychology, 6, 85-104.

Nikmanesh, Z., Kazemi, Y., \& Khosravy, M. (2014). Study role of different dimensions of emotional self-regulation on addiction potential. Journal of Family and Reproductive Health, 8(2), 69-72.

Oktuğ, Z. (2010). Gender differences in Internet addiction and tendency to express emotions. Cyberpsychology: Journal of Psychosocial Research on Cyberspace, 1, 39-53.

Özcan, S., \& Gokcearslan, S. (2013). An outcome evaluation study on Internet addiction. Global Journal on Technology, 3, 790-795.

Papalia, D. E., Olds, S. W., \& Feldman, R. D. (2009). Human development (11th ed.). New York, NY: McGraw-Hill.

Parker, J. D. A. (2005). The relevance of emotional intelligence for clinical psychology. In R. Schulze \& R. D. Roberts (Eds.), Emotional intelligence: An international handbook (pp. 271-287). Ashland, OH: Hogrefe and Huber.

Parker, J. D. A., Taylor, R. N., Eastabrook, J. M., Schell, S. L., \& Wood, L. M. (2008). Problem gambling in adolescence: Relationships with internet misuse, gaming abuse and emotional intelligence. Personality and individual differences, 45, 174-180.

Pestana, M. H., \& Gageiro, J. N. (2014). Análise categórica, árvores de decisão e análise de conteúdo em ciências sociais e da saúde com o SPSS. Lisboa, Portugal: Edições Lidel.

Pontes, H. M., Griffiths, M. D., \& Patrão, I. M. (2013). Internet addiction and loneliness among children and adolescents in the education setting: An empirical pilot study. Aloma: Revista de Psicologia, Ciències de l'Educació i de l'Esport, 32(1), 91-98.

Reisoğlu, İ., Gedik, N., \& Goktas, Y. (2013). Relationship between preservice teachers' levels of self-esteem, emotional intelligence and problematic internet use. Education and Science, 38(170), 152-167.

Romano, M., Osborne, L. A., Truzoli, R., \& Reed, P. (2013). Differential psychological impact of internet exposure on internet addicts. PLoS One, 8, e55162. Retrieved from http://dx.doi.org/10.1371/journal. pone. 0055162 
Rooy, D. L. V., Alonso, A., \& Viswesvaran, C. (2005). Group differences in emotional intelligence scores: Theoretical and practical implications. Personality and Individual Differences, 38, 689-700.

Samarein, Z. A., Far, N. S., Yeklesh, M., Tahmasebi, S., Ramezani, F. Y. V. \& Sandi, L. (2013). Relationship between personality traits and internet addiction of students at Kharazmi university. International Journal of Psychology and Behavioral Research, 2, 10-17.

Sato, T. (2006). Internet addiction among students: Prevalence and psychological problems in Japan. Japan Medical Association Journal, 49(7-8), 279-283.

Schutte, N. S., Malouff, J. M., \& Bhullar, N. (2009). The Assessing Emotions Scale. In C. Stough, D. Saklofske\& J. Parker (Eds.), The assessment of emotional intelligence (pp. 119-135). New York, NY: Springer.

Schutte, N. S., Malouff, J. M., Hall, L. E., Haggerty, D. J., Cooper, J. T., \& Golden, C. J. (1998). Development and validation of a measure of emotional intelligence. Personality and Individual Differences, 25, 167-177.

Shazad, S., \& Bagum, N. (2012). Gender differences in trait emotional intelligence: A comparative study. Business Review, 7(2), 106-112.

Silva, S. (2014). Quase três quartos dos jovens têm sinais de dependência da Internet. O Público, 7(19). Retrieved from http://www.ispa.pt/ ficheiros/noticias/03-11-014_quase_tres_quartos_dos_jovens_tem_ sinais_de_dependencia_da_internet_publico-web.pdf

Snowden, A., Stenhouse, R., Young, J., Carver, H., Carver, F., \& Brown, N. (2014). The relationship between emotional intelligence, previous caring experience and mindfulness in student nurses and midwives: A cross sectional analysis. Nurse Education Today, 35, 152-158.

Veiga-Branco, A., \& Lopes, T. (2012). Nursing emotional competence profile: Exploratory study in continued care national network. Paper presented at the IEA-EEF European Congress of Epidemiology, Porto, Portugal.

Widyanto, L., \& McMurran, M. (2004). The psychometric properties of the Internet Addiction Test. Cyberpsychology and Behavior, 7(4), 443-450.

Wieland, D. M. (2014). Internet addiction: Opportunities for assessment and treatment by psychiatric-mental health nurses. Journal of Psychosocial Nursing, 52(7), 3-5.

Wong, C. S., \& Law, K. S. (2002). The effects of leader and follower emotional intelligence on performance and attitude: An exploratory study. The Leadership Quarterly, 13, 243-274.

Yen, C. F., Ko, C. H., Yen, J. Y., Chang, Y. P., \& Cheng, C. P. (2009). Multi-dimensional discriminative factors for Internet addiction among adolescents regarding gender and age. Psychiatry and Clinical Neurosciences, 63, 357-364.

Ying, Y., \& Wenbin, G. (2011). Psychological and behavioral characteristics of severe internet addicts. Retrieved from http://pal.ist.psu.edu/ cscw2011cpp/Ying_Ye_0107.pdf

Young, K. S. (1998). Internet addiction: The emergence of a new clinical disorder. Cyberpsychology and Behavior, 1, 237-244. 